\title{
Relationship between Brain Waves and Examination Achievements
}

\author{
Yoshihiro Kokubo *, Yoshihiko Shoji ${ }^{\dagger}$
}

\begin{abstract}
The relationship between a student's concentration and performance is examined. We presume that the student's grades depend on the student's motivation and concentration. Moreover, when students are concentrating on a lesson, they should be motivated to learn. In order to elucidate student motivation during a lesson, we examine the relationship between the time that concentration is maintained, based on brain waves, and successive exam scores. Students who focused longer earned better grades or showed a significant improvement between the first and second tests. Although brain waves represent the extent of the student's concentration during the exercise, the brain wave also shows the activity of his/her brain. Students who are actively thinking would exhibit different features in brain waves compared to students who were passively listening or just recalling information. In our measurements, the brain waves of students were acquired during usual classes and were compared with the results of the subsequent tests.
\end{abstract}

Keywords: learning, motivation, concentration, brain wave, attention, meditation

\section{Introduction}

Educational improvement is an urgent subject at the University of Hyogo. Many faculty members have noted that students' grades are dropping at our university. The reason for this is believed to be unique to Japan. Although the admission capacity of universities in Japan is increasing, the number of high school students is decreasing.

Unfortunately, teachers do not have good ideas or tools to improve this situation. Even if teachers implore students to study, such sincere pleas do not significantly impact students who are not motivated. We presume that there is a significant relationship between students' active motivation and their grades, and that there is a weak relationship between a teacher's recommendation (guidance) and students' grades.

Whether a student is motivated cannot be determined by looking only at the classroom situation. The motivation mentioned in the present paper drives a student to act and concentrate with a single goal in mind. A simple method by which to determine the state of a student's thinking is to measure their brain waves. If students are concentrating on a lesson, they should be motivated. However, the opposite is not necessarily true. In other words, students may be motivated even if they are not concentrating. The reason for this is that concentration is not

* Graduate School of Engineering, University of Hyogo, Hyogo, Japan

$\dagger$ Laboratory of Advanced Science and Technology for Industry, University of Hyogo, Hyogo, Japan 
necessary if the task is easy. In the present study, we investigate the relationship between student concentration and achievement using brain wave recorders. Our data was obtained in a "Seminar of Electric Circuits," which is a compulsory course for first-year students at our university. Our system would provide information to teachers on their own lectures and would help them to reconsider their teaching style.

We used a brain wave sensor to determine the emotional state of students. We chose this sensor because the brain wave data would be convincing for engineering and science professors. Another reason was that some good brain wave sensors, which are inexpensive, easy to use, reliable, and place a low burden on subjects, are now commercially available. Recently, many studies on reading human emotions with brain waves have been reported [1][2][3][4]. Researchers first classified emotions and accumulated large amounts of data in a database for each brain wave frequency as they deliberately invoked a feeling. When actually reading emotions, they implemented a method by which to compare the components of the brain waves to the brain wave components in the database. The closest component in the database was then determined to be the emotion at a given time. The brain waves in the dataset were usually as short as a few seconds.

A number of studies have reported that the beta brain wave is associated with increased mental activity [5][6][7][8]. S. Yang et al. [9] develops an attention aware system capable of recognizing students' attention levels accurately based on EEG signals. K. Yoshida et al. [10] analyzed the relationship between alpha and beta brain waves using a simple electroencephalograph. The results revealed that measurement of the beta/alpha ratio enables the evaluation of the activity and vital activity of the human brain. Using this technique, K. Yoshida et al. proved that the beta/alpha ratio had a larger shift when students tried to answer questions in foreign language classes as compared to math classes.

In our measurements, the brain waves of students were acquired during usual classes and were compared with the results for subsequent tests. We did not record the brain waves during the test.

\section{Measurements of Brain Waves during Class}

[Design of this study]

MindWave Mobile by NeuroSky was used for the brain wave measurements [11]. This device is easy to put on and remove, and the discomfort of wearing device is negligible because the device is lightweight and is connected via Bluetooth. MyndPlayer Pro Ver. 2.3 by NeuroSky was used as the software. This software can not only record the actual waveform of a brain wave, but can also analyze the frequency components: $\delta$ waves $(0.5 \mathrm{~Hz}$ to $3 \mathrm{~Hz}), \theta$ waves $(4 \mathrm{~Hz}$ to $7 \mathrm{~Hz}$ ), low $\alpha$ waves $(8 \mathrm{~Hz}$ to $9 \mathrm{~Hz}$ ), high $\alpha$ waves ( $10 \mathrm{~Hz}$ to $12 \mathrm{~Hz}$ ), low $\beta$ waves ( $13 \mathrm{~Hz}$ to 17 $\mathrm{Hz}$ ), high $\beta$ waves ( $18 \mathrm{~Hz}$ to $30 \mathrm{~Hz}$ ), low $\gamma$ waves $(31 \mathrm{~Hz}$ to $40 \mathrm{~Hz}$ ), and midrange $\gamma$ waves (41 $\mathrm{Hz}$ to $50 \mathrm{~Hz}$ ). A student's attention is more strongly related to beta waves, whereas a student's meditation is more strongly related to alpha waves [12]. However, we used the attention and meditation signal provided by the software rather than the primary beta or alpha waves.

[Participant information]

A total of three students participated as references. The brain waves were measured while (1) a student listened to a regular lecture, (2) a student solved problems quickly, and (3) a student thought carefully. Data for cases (1) and (2) were obtained for a student in the medical department (fifth-year student studying for the national qualifying exam) because, such students commonly watch video lectures and try to answer past exam questions. Such students are generally required to memorize than think. Data for case (3) were obtained for a student in 
the School of Science taking English lessons. The student was required to understand the syntax of English sentences during the brain wave measurements.

[Procedure for conducting the experiment]

Figure 1 shows the attention and meditation data of the brain waves while a student in the medical department is receiving a lesson. Figure 2 shows the brain waves for the case of solving past problems on the National Medical Practitioners Qualifying Examination (NMPQE), which consists of 400 questions with approximately two minutes allowed per question. This exam requires memorization and quick responses rather than deep analytical thought. Figure 3 shows the brain waves while the reference student is actively engaged in self-study. This figure shows a remarkable separation between the distribution of attention and meditation. In other words, there appears to be a more notable difference in intensity between attention and meditation when actively concentrating and studying, as compared to when passively listening to a lesson or remembering fragmental memories. In Figure 3, as an example, for the first 17 to 18 minutes, the intensity of the attention distribution is higher than that of the meditation distribution, implying that the student is concentrating during this period. Several minutes later, the student's concentration appears to be broken, and the intensity of meditation becomes higher than that of attention. After approximately 25 minutes, the student's concentration appears to be restored, and attention again becomes dominant. A value of 0 indicates that the signal could not be captured. The absolute magnitude of each attention and meditation measurement depends on the contact condition of the electrodes and the electrical conductivity of the body. Thus, the absolute values cannot be used to compare the emotional states of two different students. In both cases, since attention and meditation are recorded every second, and the distributions of the attention and meditation are mixed in Figures 1, 2, and 3, the figures are too complex and are difficult to understand.

Therefore, it is considered to be appropriate to adopt the attention/meditation ratio (hereinafter abbreviated as $\mathrm{A} / \mathrm{M}$ ratio), which does not depend on the attention and meditation distributions. Moreover, in order to facilitate understanding, the time average of the $\mathrm{A} / \mathrm{M}$ ratio was taken. The one-minute averages for the data in Figures 1, 2, and 3 are shown in Figures 4, 5, and 6, respectively. Values greater than one indicate that the student is concentrating, whereas values lower than one indicate that the student is meditating. A value of 0 indicates that data could not be acquired. Although the A/M ratio is greater than one for only 17 to 18 minutes in Figure 6, the results indicate that concentration is generally maintained.

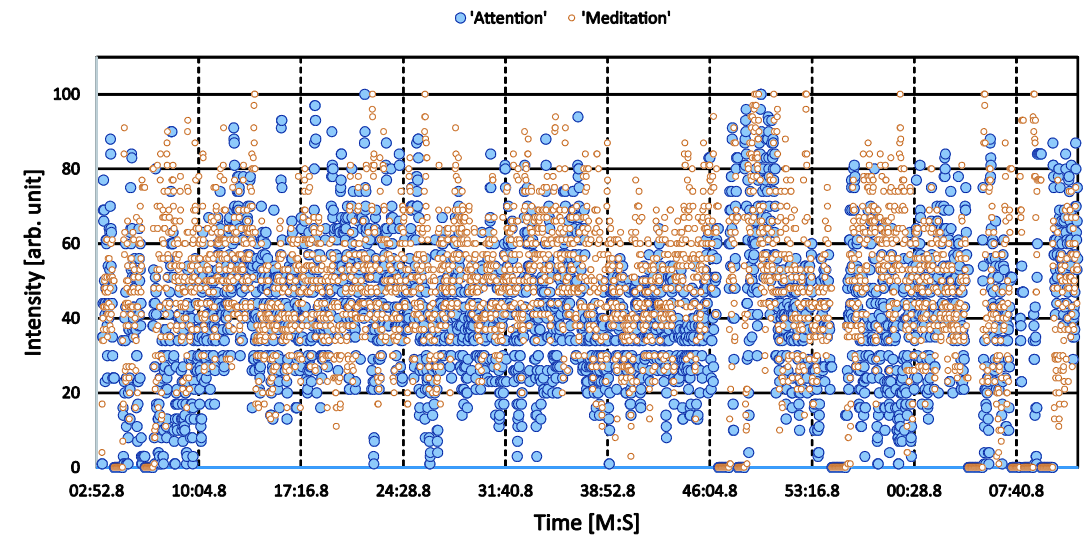

Figure 1: Attention and meditation for brain waves of a medical student listening to a lecture. 


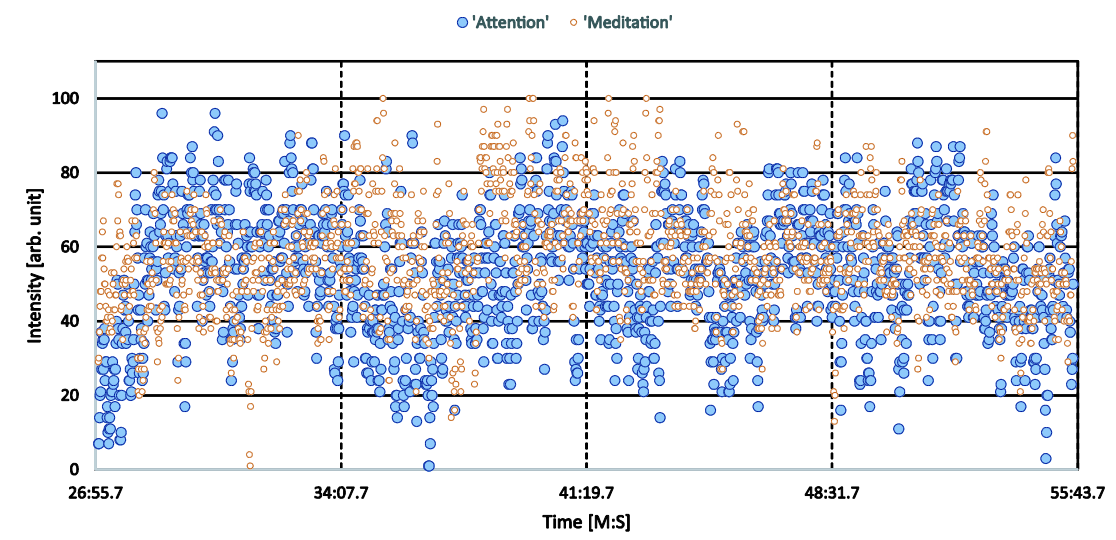

Figure 2: Attention and meditation for brain waves of a medical student solving test problems.

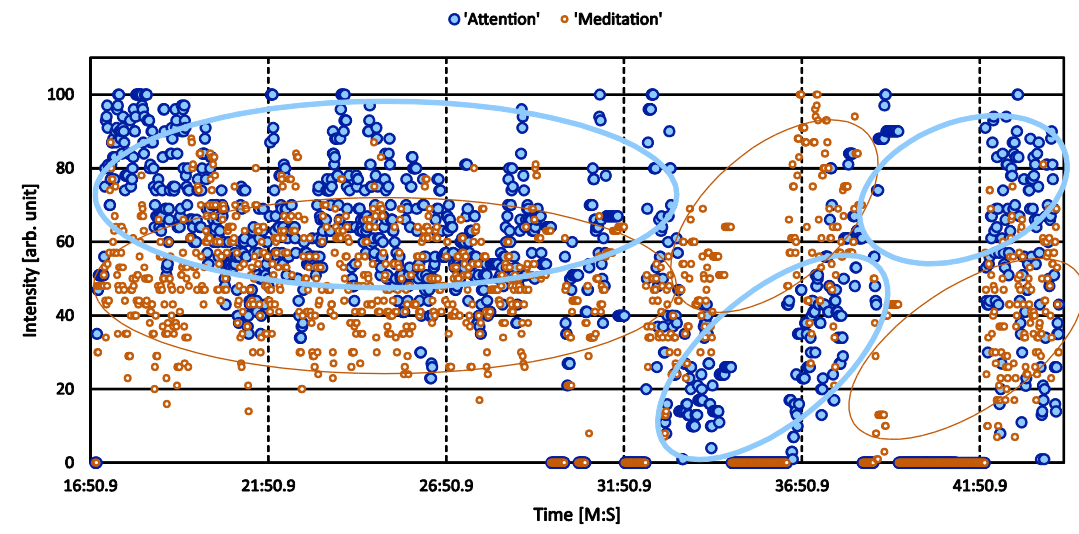

Figure 3: Attention and meditation for brain waves of a student of the University of Tokyo reading an English book.

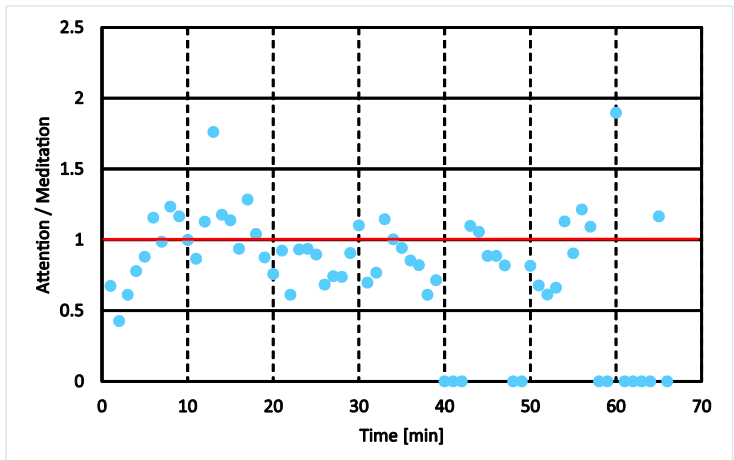

Figure 4: Attention/meditation ratio taken as an average for one minute of a medical student listening to a lecture. 


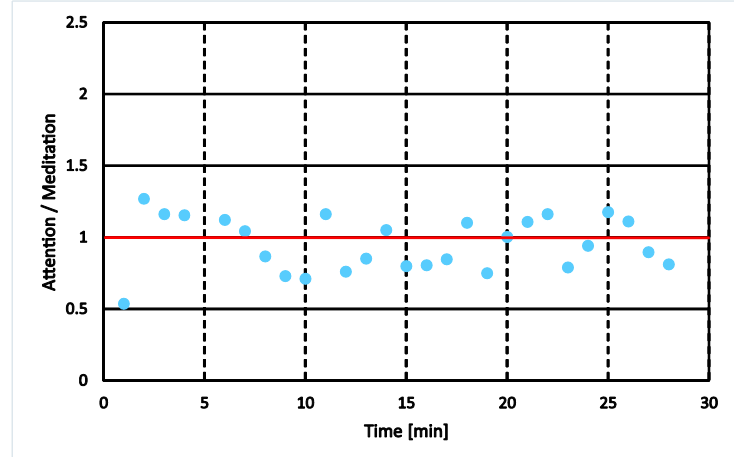

Figure 5: Attention/meditation ratio taken as an average for one minute of a medical student solving national examinations.

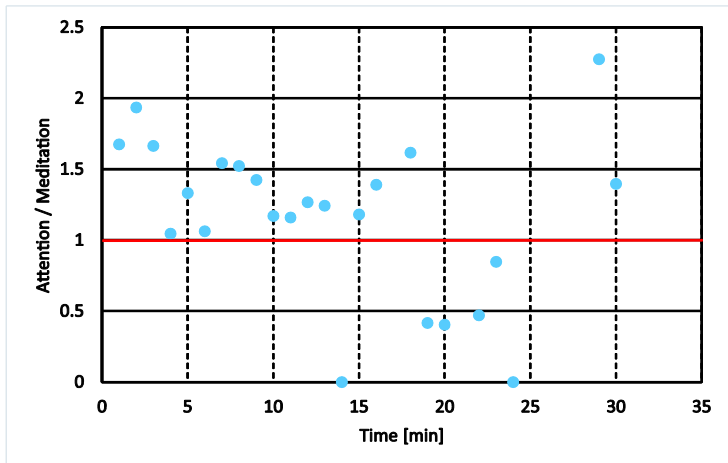

Figure 6: Attention/meditation ratio taken as an average for one minute of a student of the University of Tokyo reading an English book.

The academic ability required in order to enroll in the School of Engineering at our university requires a correct answer rate of approximately $60 \%$ to $70 \%$ on the National Center Test for University Admissions. The brain wave measurement participants had this minimum academic ability, i.e., the participants were in the top quarter of their class. Although a larger group is better, the brain waves of only eight students were measured due to the limited number of student volunteers.

Based on the above considerations, we selected the Seminar of Electric Circuits as the class for experimentation. This class presents exercises for students to solve problems in exercise books by themselves during the seminar. The Seminar of Electric Circuits also involves two exams, but brain waves were measured during a seminar close to the time of the second test. Table 1 shows the results of the test scores for the eight students whose brain waves were measured. A total of 143 students took two tests, the average scores of which were $58.8 \%$ and $81.4 \%$. Since brain wave data were obtained just before the second test, focusing on the results of the second test, only Student B exceeded the average score of the second test. The increase in the score from the first test to the second test for Student G was highest, and Student E had the worst score among the eight students. 
Table 1: Test scores and results of brain waves for the eight students.

\begin{tabular}{llllll}
\hline Students & $\begin{array}{l}\text { Score of the } \\
\text { first test } \\
\text { (class aver- } \\
\text { age was } \\
58.8 .)\end{array}$ & $\begin{array}{l}\text { Score of } \\
\text { the second } \\
\text { test (class } \\
\text { average } \\
\text { was 81.4.) }\end{array}$ & $\begin{array}{l}\text { Increased } \\
\text { score from } \\
\text { the 1st to } \\
\text { the 2nd test }\end{array}$ & $\begin{array}{l}\text { Time ratio when } \\
\text { A/M ratio is } \\
\text { larger than 1 } \\
\text { (except the } \\
\text { dropped values) }\end{array}$ & Features \\
\hline A & 60 & 70 & +10 & 0.44 & \\
B & 45 & 98 & +53 & 0.76 & $\begin{array}{l}\text { Highest 2nd test score } \\
\text { among the 8 students }\end{array}$ \\
C & 87 & 79 & -8 & 0.50 & \\
D & 40 & 70 & +30 & 0.57 & \\
E & 47 & 38 & -9 & 0.37 & $\begin{array}{l}\text { Lowest 2nd test score } \\
\text { among the 8 students }\end{array}$ \\
F & 64 & 80 & +16 & 0.42 & \\
G & 8 & 65 & +57 & 0.73 & $\begin{array}{l}\text { Highest increased score } \\
\text { from 1st to 2nd tests } \\
\text { among the 8 students }\end{array}$ \\
H & 47 & 46 & -1 & 0.63 & \\
\hline
\end{tabular}

Figures 7(a) through 7(h) show the A/M ratio as an average for one minute for Students A through H, respectively. Among these eight students, only Student B scored above the average. Figure 7(b) shows the brain wave data of this student close to the time of the second test. Student $\mathrm{B}$ had an $\mathrm{A} / \mathrm{M}$ ratio greater than one for more than 30 minutes, indicating that the student focused during the class.

Figure 7(e) shows the A/M ratio of Student E, who scored the lowest among the eight students on the second exam. Most of the time, the A/M ratio of Student E was less than one, indicating that concentration was not sustained.

However, among the students who scored below average on the second test, only one student (Student $\mathrm{G}$ ) had an $\mathrm{A} / \mathrm{M}$ ratio greater than one for a significant time ( $>50 \mathrm{~min}$ ) (Figure $7(\mathrm{~g})$ ). Although the student scored below average on the second test, the marked improvement between the first and second exams is likely due to significant concentration during the lesson. Table 1 also shows the time ratio when the $\mathrm{A} / \mathrm{M}$ ratio is larger than one (except for the dropped values) besides test scores. Only Students B and G had a time ratios exceeding 0.7, and only Student $\mathrm{E}$ had a time ratio smaller than 0.4. Based on this data, we believe that a large time ratio as compared to the $\mathrm{A} / \mathrm{M}$ ratio in the lesson leads to good grades.

Figures 8 (a) through 8 (c) show the frequency distributions of the average intensity of brain waves for 10 minutes beginning 20 minutes after the start. However, the vertical unit is arbitrary because the absolute value depends on the contact condition of the electrodes. Students B and $\mathrm{G}$, who exhibited a high degree of concentration, had similar brain wave distributions. The magnitude of high beta waves was approximately the same as that of the low alpha waves, although the magnitude of Student E's high beta waves, which had a low degree of concentration, was smaller than the magnitude of his low alpha waves. 


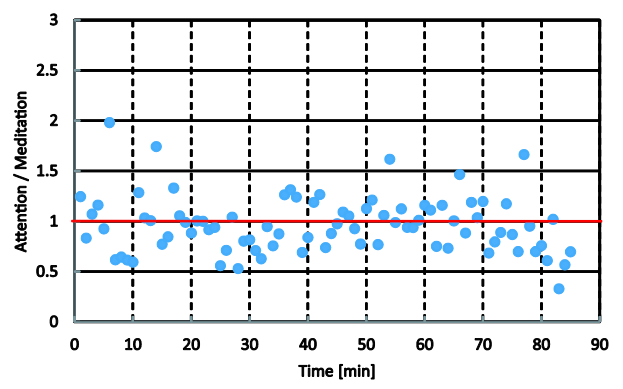

(a) Student A

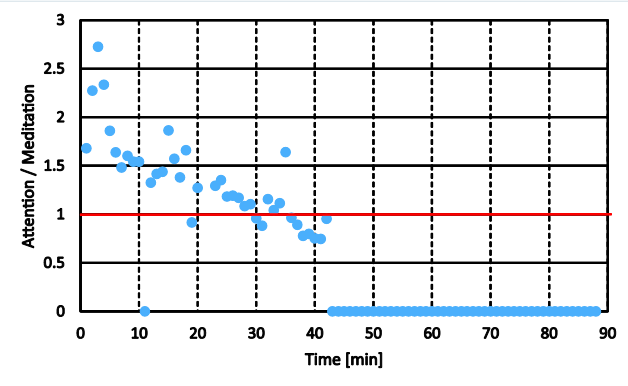

(b) Student B

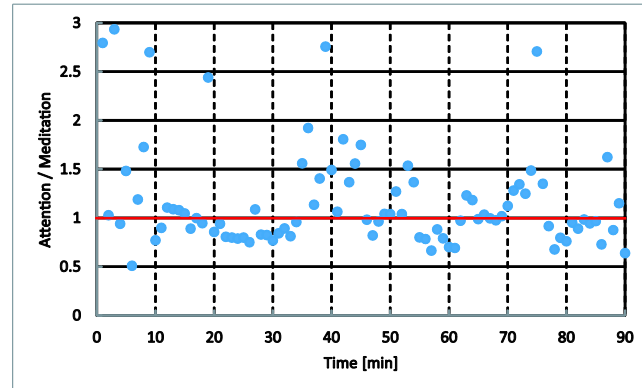

(c) Student C

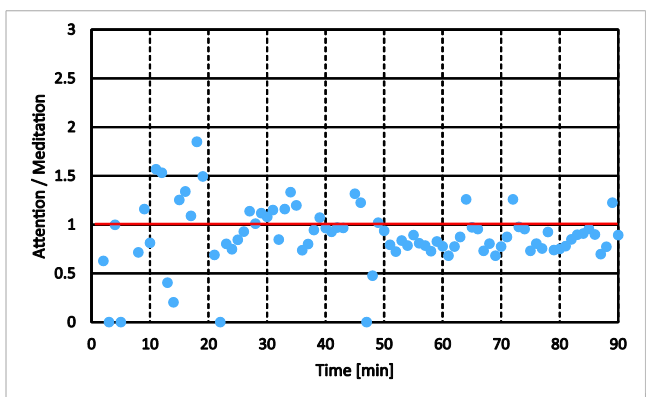

(e) Student E

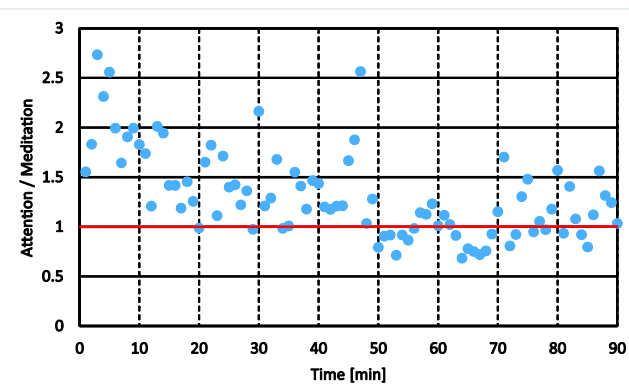

(g) Student G

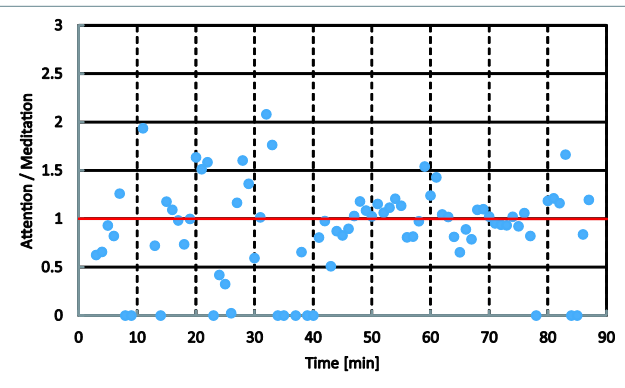

(d) Student D

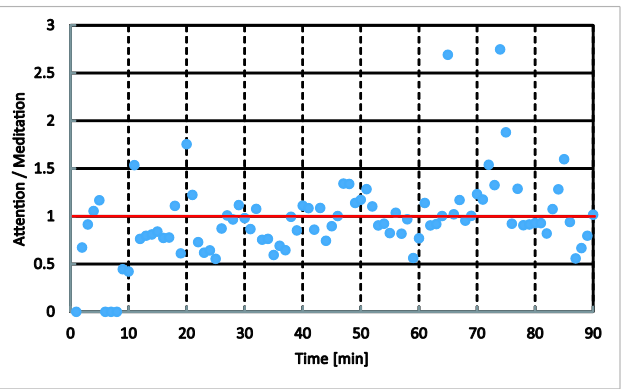

(f) Student F

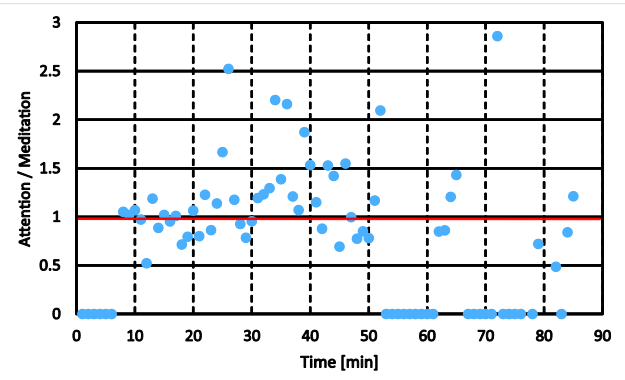

(h) Student H

Figure 7. Attention/meditation ratio taken as an average for one minute. 


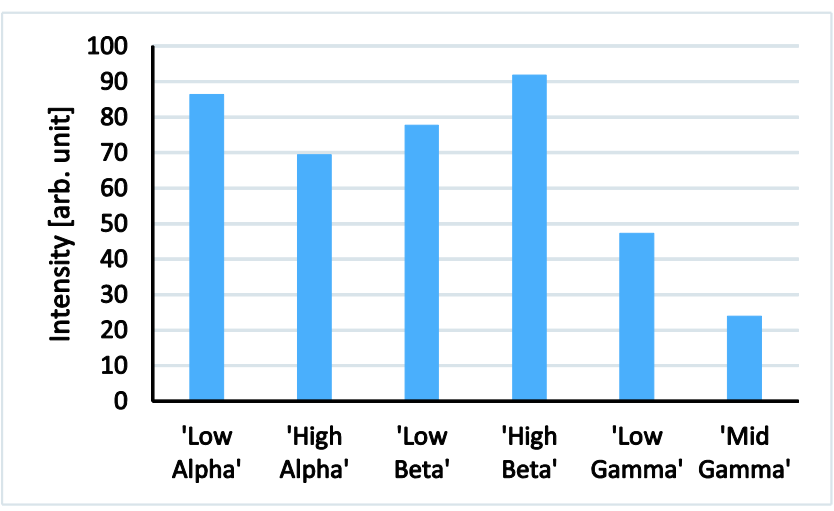

(a) Student B

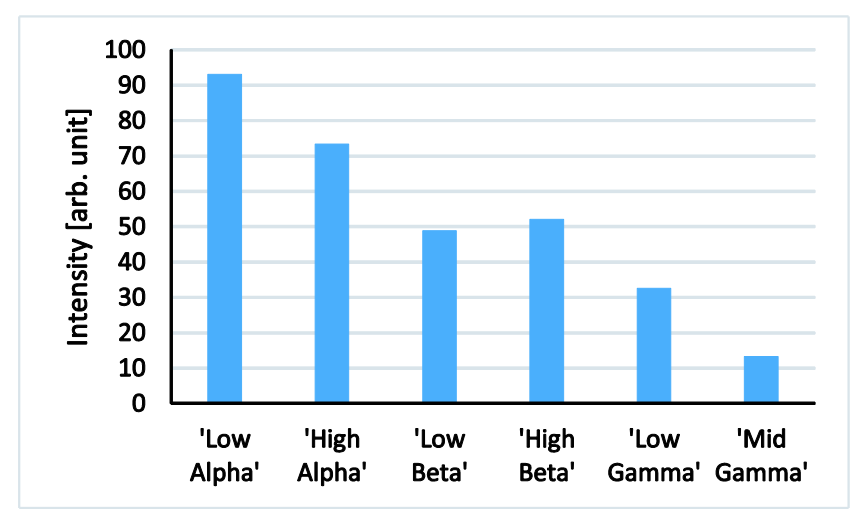

(b) Student E

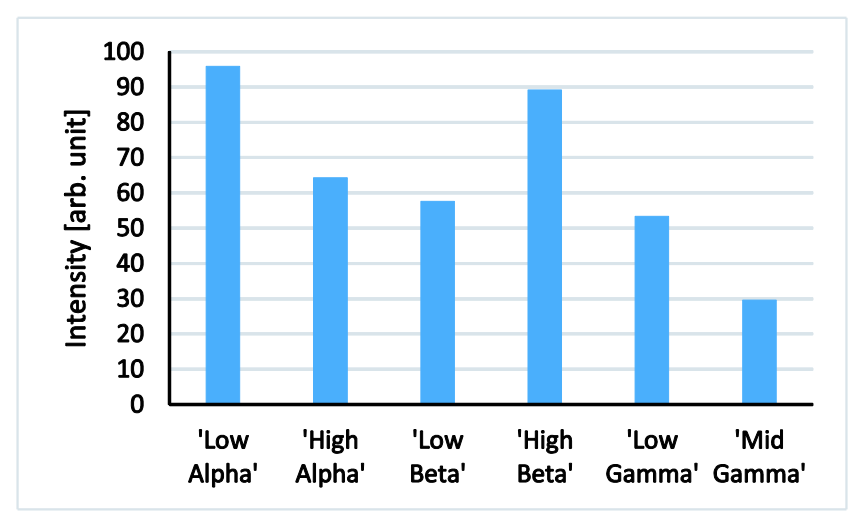

(c) Student G

Figure 8 Average intensity of brain waves for Students B, E, and G for a period of 10 minutes beginning after 20 minutes from the start.

\section{Conclusion}

Brain wave measurements were analyzed in order to elucidate student achievement and the degree of concentration during class. In order to avoid unstable calibration of each student, we considered an attention/meditation ( $\mathrm{A} / \mathrm{M})$ ratio of greater than one, which indicates concentration, whereas an $\mathrm{A} / \mathrm{M}$ ratio of less than one indicates relaxation or distraction. We used $\mathrm{A} / \mathrm{M}$ $=1$ as a criterion, although there was no clear basis for this. 
We measured brain waves in three cases: (1) listening to a regular lecture, (2) solving problems quickly, and (3) thinking carefully. Cases (1) and (2) did not sustain the condition of $\mathrm{A} / \mathrm{M}>1$. Case (1) may involve listening to a regular lecture passively, and case (2) may involve recalling previously memorized information. Concentration is difficult to observe in brain waves. Only case (3) involves thinking carefully (e.g., silently reading an English book), and the condition of $\mathrm{A} / \mathrm{M}>1$ is sustained. Thus, we selected the Seminar of Electric Circuits as the class for experimentation. This class presents exercises for students to solve problems in exercise books by themselves during the seminar. Although our brain wave data are for only eight students, it is thought that brain waves meeting the $\mathrm{A} / \mathrm{M}=1$ criterion are correlated with a student's grade.

Thus, whether the one-minute average of the A/M ratio is larger or smaller than one determines the concentration level, which is subsequently compared to the test scores. The analysis revealed the following:

1. Students who maintained $\mathrm{A} / \mathrm{M}$ ratios greater than one for approximately 30 to 40 minutes are considered to have concentrated during the lecture.

2. Students who maintained $\mathrm{A} / \mathrm{M}$ ratios greater than one for periods longer than approximately 30 minutes scored better on the second test or scored significantly higher on the second test than on the first test.

3. The above findings indicate that a student who maintained concentration during class would receive a good grade.

\section{References}

[1] C. Guger et al.,"How many people are able to operate an EEG-based brain computer interface (BCI)?, IEEE Trans. Neural Systems and Rehabilitation Engineering, 11(2): 2003, pp.145-147.

[2] S. Suzuki et al., "A human tracking system on the robot with face detection", INFORMATION-An International Interdisciplinary Journal, Vol. 13, No. 1, 2010, pp. 137-143.

[3] K. S. Kassam et al., "Identifying Emotions on the Basis of Neural Activation", PLOS ONE, 8 (6), 2013, pp.1-12.

[4] N. Tokita et al., "Brain Wave Emotion Judge System using a Regression Analysis", Forum on Information Technology 2014, the Institute of Electronics, Information and Communication Engineers, FIT2014, 2014, pp.321-322.(in Japanese)

[5] D. Giannitrapani, “The Role of 13-Hz Activity in Mentation”, The EEG of Mental Activities, 1988, pp. 149-152.

[6] A. Wrobel, "Beta activity: A carrier for visual attention", Acta Neurobiologiae Experimentalis, 2000, pp. 247-260.

[7] M. Singh et al., "Change in Brain wave rhythms during tasks involving Attention and Working memory", International Journal of Information Technology and Management, 7(2), 2014, pp. 71-97.

[8] K. Yoshida et al., "Evaluation of the change of work using simple electroencephalography", 
KES'2013, Proceedings, Knowledge-Based Intelligent Information and Engineering Systems, 2013, PP.1817-1826.

[9] S. Yang et al., "Assessing the Attention Levels of Students by Using a Novel Attention Aware System based on Brainwave Signals", 4th International Congress on Advanced Applied Informatics, 2015, pp. 379-384.

[10] K. Yoshida et al., "Analysis comparison of brain waves at the learning status by simple electroencephalography", KES'2012, Proceedings, Knowledge-Based Intelligent Information and Engineering Systems, 2012, pp. 1817-1826.

[11] MindWave Mobile, http://store.neurosky.com/pages/mindwave/

[12] NeuroSky Support Site, http://support.neurosky.com/kb/science/what-is-esense 